\title{
150 years of the North Magnetic Pole
}

\author{
from David R. Barraclough and S. R. C. Malin
}

ON June 1st, 1831, Commander James Clark Ross "fixed the British flag on the spot, and took possession of the North Magnetic Pole and its adjoining territory, in the name of Great Britain and King William the Fourth"'. The spot referred to was at $70^{\circ} 5^{\prime} 17^{\prime \prime} \mathrm{N}, 96^{\circ} 46^{\prime} 45^{\prime \prime} \mathrm{W}$ where the mean value of magnetic dip, observed over nearly 24 hours, was $89^{\circ} 59^{\prime}$. This was, as nearly as could be determined with the instruments then available, the position of the North Magnetic Pole (where the dip would be exactly $90^{\circ}$ ). Commander Ross thus became the first man knowingly to set foot on (there was an eskimo settlement nearby) the North Magnetic Pole.

James Clark Ross was not a stranger to Arctic exploration. After entering the Royal Navy at the age of 12 he served under his uncle, John Ross, for six years. In 1818 he was a member of the expedition, led by John Ross, which began the series of nineteenth century assaults on the NorthWest Passage. For the next nine years the younger Ross was almost continuously in the Arctic, serving under Parry on his four famous expeditions.

In 1829 John Ross organized an expedition, financed by Felix Booth, the gin distiller, to make yet another attempt to find the North-West Passage. As his second-in-command he chose his by now very experienced nephew. It is not clear how importantly the discovery of the position of the North Magnetic Pole figured in the original plans for the

David R. Barraclough and S. R. C. Malin are at the Institute of Geological Sciences, Edinburgh.

probability of transmission from an infectious male to a susceptible female is around $0.5-0.7$; since a new sexual encounter typically involves more than one sexual intercourse, the net female-to-male transmission probability may be around 0.5 , and the male-to-female around 0.9 , per encounter. These detailed values are of less significance in the models than is their ratio, namely around 1:2 (female-to-male versus male-to-female).

Broadly, Hethcote, Yorke and Nold ${ }^{7}$ consider three control strategies. Strategy AW involves the general screening of females, by testing cultures taken from women who use certain designated health facilities. The corresponding strategy AM does the same thing for males. Strategies BW and BM trace females and males, respectively, to whom an infection has been spread by a diagnosed infected individual. Strategy $\mathrm{CW}$ identifies infectious females by the men they have infected; strategy CM correspondingly identifies infectious males by their women infectees. In short, strategy A takes a slice

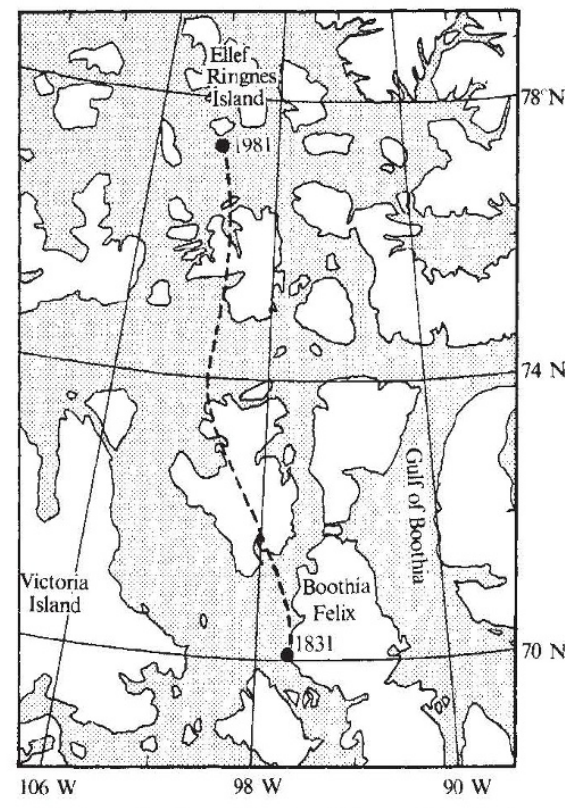

Path of the North Magnetic Pole, $1831-1981$.

expedition, but it was ultimately to prove the major achievement, since the attempt to find the North-West Passage failed. In fact, having spent the first winter frozen in on the east coast of Boothia Felix (now the Boothia Peninsula), the expedition ship Victory was able to move only about $8 \mathrm{~km}$ northwards during the next two years in an unsuccessful attempt to escape from what had proved to be a dead end. During this enforced stay in Boothia Felix, the younger Ross led several sledging expeditions across and along the peninsula. He also made a

in time, B pursues the chain downstream, and $\mathrm{C}$ pursues it upstream.

Although the quantitative details depend on the specific parameters chosen in the various models, strategy $C$ is always more effective than A, which in turn is markedly superior to $\mathrm{B}$. YHN explain this by observing that asymptomatics are more important transmitters than symptomatics because they are infectious for a longer time, and that core persons are more important transmitters because they contact more people while they are infectious. Strategy $\mathrm{C}$ has a high likelihood both of identifying very active core individuals and of identifying asymptomatics; strategy $\mathrm{A}$, although relatively ineffective in locating core people, tends to find asymptomatics; while strategy $B$ is not particularly effective in finding either core individuals or asymptomatics. Within any one strategy, finding infectious males by $\mathrm{M}$ controls is generally at least as effective at reducing prevalence levels as is finding infectious females by $\mathrm{W}$ controls.

Hethcote, Yorke and Nold ${ }^{7}$ sensibly series of geomagnetic observations from which he estimated the probable position of the North Magnetic Pole to be within range of a sledging party. Accordingly, during the last summer in Boothia, James Clark Ross set out to discover the Pole's position and succeeded in doing so.

The story of how the expedition finally extricated itself and was almost miraculously rescued after a fourth winter in the Canadian Arctic cannot be told here. John Ross was knighted in recognition of his achievements and his nephew became the acknowledged leader in the field of polar exploration. James Clark Ross was himself awarded a knighthood on the return of his successful Antarctic expedition during which he came close to, but was unable to reach, the South Magnetic Pole.

The North Magnetic Pole has moved about $800 \mathrm{~km}$ north during the 150 years since its discovery, as indicated in the figure. Its present position ${ }^{2}$ is about $77.3^{\circ} \mathrm{N}, 101.8^{\circ} \mathrm{W}$

Sir James Clark Ross's achievement, together with those of other British geomagneticians, is being marked in an exhibition 'The Earth is a Magnet' to be held in the Royal Scottish Museum, Edinburgh, from June 8 until the end of August.

\footnotetext{
Report of Commander, now Captain, James Clark Ross, RN, FRS, FLS in Narrative of a Second Voyage in Search of a North-West Passage, and of a Residence in the Arctic Regions during the years 1829, 1830, 1831, 1832, 1833 (Webster, London, 1835).

2. Magnetic Declination Chart 1980.0, Canada (Division of Geomagnelism, Department of Energy, Mines and Resources, Ottawa).
}

conclude by stressing that "the relative merits of the various control procedures depend not only on the effectiveness per discovery in reducing prevalence, but also on the cost of discovering an infective by the procedures". If field studies can be designed to evaluate the cost in dollars, or at least the relative costs, for the discovery and cure of one person by each of the general strategies, the way will be opened to the rational design of 'cost effective' programmes. "Different cities or states might come to different conclusions based on the differing nature of their populations ${ }^{7}$."

\footnotetext{
1. United States Morbidity and Mortality Weekly Report $28,605(1980)$

2. Cooke, K. L. \& Yorke, J. A. Math. Biosci. 16, 75 (1973). 3. Reynolds, G. H. \& Chan, Y. K. Bull. Inst. int. Statist. 106, 264 (1975).

4. Hethcote, W. H. Math. Biosci. 28, 335 (1976).

5. Constable, G. M. Bull. Inst. int. Statist. 106, 256 (1975). 6. Yorke, J. A., Hethcote, H. W.\& Nold, A. Sex. Trans. Dis. 5, 51 (1978).

7. Hethcote, H. W., Yorke, H. A. \& Nold, A. Math. Biosci. (in the press).

8. Wiesner, P. J. \& Thompson, S. E. Disease-a-Month 27 (5), 1 (Feb., 1980).
} 